\title{
Missense Variants in PAX4 Are Associated with Early- Onset Diabetes in Chinese
}

\author{
Aibo Gao $\cdot$ Bin Gu $\cdot$ Juan Zhang $\cdot$ Chen Fang $\cdot$ Junlei Su • \\ Haorong Li · Rulai Han · Lei Ye · Weiqing Wang · Guang Ning • \\ Jiqiu Wang · Weiqiong Gu (D)
}

Received: September 15, 2020 / Accepted: October 27, 2020 / Published online: November 20, 2020

(c) The Author(s) 2020

\begin{abstract}
Introduction: East Asians are more susceptible to early-onset diabetes than Europeans and exhibit reduced insulin secretion at earlier stages. PAX4 plays a critical role in the development of $\beta$-cells. The dysfunction-missense variants PAX4 R192H and PAX4 R192S are common in East Asians but rare in Europeans.
\end{abstract}

Aibo Gao and Bin Gu share joint first co-authorship.

Electronic supplementary material The online version of this article (https://doi.org/10.1007/s13300020-00960-5) contains supplementary material, which is available to authorized users.

A. Gao - B. Gu · J. Zhang . J. Su . H. Li . R. Han . L. Ye · W. Wang · G. Ning · J. Wang (ه) · W. Gu (ه) Department of Endocrinology and Metabolism, Ruijin Hospital, Shanghai Jiao Tong University School of Medicine (SJTUSM), Shanghai 200025, China

e-mail: wangjq@shsmu.edu.cn

W. Gu

e-mail: weiqionggu@163.com

A. Gao

National Research Center for Translational Medicine, Ruijin Hospital Affiliated to Shanghai Jiao Tong University School of Medicine, Shanghai 200025, China

C. Fang

The Second Affiliated Hospital of Soochow University, Soochow 215004, China
Therefore, we aim to investigate the diabetesassociated genes, including PAX4 R192H/S, in East Asians with early-onset diabetes.

Methods: Exome variants of 80 Chinese earlyonset diabetes patients (onset age $<35$ years) after the exclusion of type 1 diabetes (T1D) were detected by a customized gene panel covering 32 known diabetes-associated genes. Then, 229 subjects with early-onset diabetes (T1D excluded) and 1679 controls from the Chinese population were genotyped to validate the association of PAX4 R192H/S with early-onset diabetes and related phenotypes.

Results: The gene panel detected 11 monogenic diabetes patients with five novel mutations among the 80 early-onset diabetes patients. Asian-specifically enriched PAX4 R192H and R192S were associated with earlyonset diabetes (R192H: OR 1.88, 95\% CI 1.37-2.60, $P=8.41 \times 10^{-5}$; R192S: OR 1.71, 95\% CI 1.17-2.51, $P=0.005)$. In early-onset diabetes patients, PAX4 R192H carriers had higher haemoglobin A1c (HbA1c) levels $(P=0.030)$ and lower $2 \mathrm{~h}$ C-peptide levels in the oral glucose tolerance test (OGTT) $(P=0.040)$; R192S carriers had lower fasting C-peptide (FCP) $(P=0.011)$ and $2 \mathrm{~h} \mathrm{C}$-peptide levels $(P=0.033)$ in OGTT than non-variant carriers.

Conclusions: The ethnic-specific enrichment of PAX4 R192H/S predisposing East Asians to earlyonset diabetes with decreased C-peptide levels may be one explanation of the discrepancy of diabetes between East Asians and Europeans. 
Clinical trial registration: ClinicalTrials.gov (NCT01938365).

Keywords: C-peptide; Early-onset diabetes; East Asian; PAX4

\section{Key Summary Points}

Why carry out the study?

East Asians are more susceptible to earlyonset diabetes than Europeans and exhibit reduced insulin secretion at earlier stages. Therefore, we explored the genetic architecture of early-onset diabetes in young Chinese.

\section{What was learned from the study?}

Asian-specifically enriched PAX4 R192H/S is associated with early-onset diabetes in Chinese population.

PAX4 R192H/S carriers have lower C-peptide levels than non-variant carriers in early-onset diabetes patients.

The ethnic-specific enrichment of PAX4 R192H/S in East Asians may partially explain the discrepancy of diabetes between the East and the West from a genetic perspective.

\section{DIGITAL FEATURES}

This article is published with digital features to facilitate understanding of the article. You can access the digital features on the article's associated Figshare page. To view digital features for this article go to https://doi.org/10.6084/m9. figshare.13200650.

\section{INTRODUCTION}

In East Asian population, the prevalence of early-onset diabetes has increased rapidly in recent years, posing serious challenges for healthcare systems [1]. Patients with early-onset diabetes are more likely to have a family history and poor metabolic control compared with patients with late onset [2], which is suggestive of the strong involvement of genetic factors underlying the pathophysiology of early-onset diabetes. Therefore, an insight into the genetic basis of early-onset diabetes may contribute to the discovery of novel pathogenic mutations and therapeutic targets [3].

Studies have reported extensive discrepancies in diabetes between East Asians and Europeans [4]. The prevalence of early-onset diabetes in East Asians is much higher than in Europeans [5]. East Asian diabetic patients usually have a younger onset age and a lower body mass index (BMI) than those in Europe, and their insulin secretion tends to decline quickly $[4,6,7]$. Of note, PAX4 plays a critical role in the development, differentiation, expansion, and survival of islet insulin-producing $\beta$-cells $[8,9]$; the missense variant $\mathrm{R} 192 \mathrm{H}$ impairs $\beta$-cell development and survival [10, 11]. Besides, PAX4 R192H and R192S were reported to be common in East Asians but rare in Europeans [12]. Thus, it would be of interest to explore the association of variants in PAX4 with early-onset diabetes in young Chinese, attempting to explain the discrepancy of diabetes between the East and the West from a genetic perspective.

Unlike the extensive genetic studies of lateonset diabetes, limited information is available on the genetic architecture of early-onset diabetes. For assessing the exome variants that may be specific in populations, gene panel testing is simple, is more economical, and has greater scalability compared with whole-genome or exome sequencing. Therefore, in the present study, we analysed the exome variants of 80 Chinese early-onset diabetes patients by a customized gene panel after the exclusion of type 1 diabetes (T1D) [2, 13]. Then, 229 Chinese earlyonset diabetes cases (T1D excluded) and 1679 controls were genotyped to validate the association of the PAX4 variants detected by the gene panel with early-onset diabetes and the related clinical features. 


\section{METHODS}

\section{Study Subjects}

This research was carried out in two phases, a discovery phase and a validation phase, and at the end the clinical features were compared (Fig. 1). In the discovery stage, 80 Chinese earlyonset diabetes patients (onset age $<35$ years) were enrolled for gene panel testing after the exclusion of 330 T1D patients [2, 13, 14]. For the association analysis of variants with earlyonset diabetes, 69 of the 80 patients and 221 age and sex-matched Chinese non-diabetic controls were enrolled. In the validation phase, an additional 160 Chinese early-onset diabetes (T1D excluded) patients genotyped PAX4 R192 variations with Sanger sequencing, and 1458 ethnicity-matched controls were enrolled to validate the association of PAX4 R192H/S with early-onset diabetes. The patients were enrolled from Ruijin Hospital and The Second Affiliated Hospital of Soochow University from October 2008 to August 2017. The controls in the discovery stage were recruited from volunteers at the Shanghai Jiao Tong University School of Medicine and were non-diabetic and not receiving any treatment for diabetes. Their whole-exome sequencing (WES) data came from a previous study [15]. The WES data of controls in validation stage came from an established database [16]. Diabetes was diagnosed if fasting plasma glucose (FPG) $\geq 7 \mathrm{mmol} / \mathrm{L}$ or $2 \mathrm{~h}$ glucose during oral glucose tolerance test $(\mathrm{OGTT}) \geq 11.1 \mathrm{mmol} / \mathrm{L}$ according to the American Diabetes Association (ADA) criteria and classified based on the SEARCH study in the discovery and validation stages $[14,17]$. Patients were excluded if they fulfilled the criteria of T1D: positive of glutamic acid decarboxylase antibody (GADA) or fasting C-peptide (FCP) $<0.8 \mathrm{ng} / \mathrm{mL}$ [17]. This study was approved by the Ethics Committee of Shanghai Ruijin Hospital, and all patients provided written informed consents. The study is registered at ClinicalTrials.gov (NCT01938365). The flow-chart of the overall study design is shown in Fig. 1.
The subjects underwent a standard $75 \mathrm{~g}$ OGTT after an overnight fast of 10-12 h. The levels of both blood glucose and C-peptide at fasting $1 \mathrm{~h}$ and $2 \mathrm{~h}$ after taking glucose were measured using an enzymatic method (Beckman CX-7 Biochemical Autoanalyzer, Brea, CA) and a radioimmunoassay kit (Roche Diagnostics, Germany), respectively, as mentioned previously $[18,19]$. Serum haemoglobin A1c (HbA1c) was measured using high-pressure liquid chromatography, and serum triglyceride and total cholesterol levels were measured using an autoanalyzer (Modular E170, Roche). Subjects also underwent comprehensive physical examination. Weight, height, waist and hip circumferences were directly measured using standardized devices, and BMI was calculated as body weight in kilograms divided by height in meters squared. Blood pressure was measured using an automated electronic device (Omron, Dalian, China).

\section{Development of the Gene Panel}

Referring to Online Mendelian Inheritance in Man (OMIM, https://www.omim.org/) and the previous study, 32 genes involved in $\beta$-cell development, insulin secretion or insulin resistance were selected to comprise the gene panel [20]. These genes included 14 maturity-onset diabetes of the young (MODY) genes, 14 neonatal diabetes mellitus (NDM) genes and 4 insulin resistance associated genes (Table S1). The mutations of these genes tend to increase the risk of early-onset diabetes [20]. All of the 566 pairs of primers for candidate genes were designed using Ion Ampliseq ${ }^{\mathrm{TM}}$ Designer of the ThermoFisher Company, and the primer design details were described at https://www.ampliseq. $\mathrm{com} /$. The panel covered all exome regions and intron-exon boundaries (target region of about $149.19 \mathrm{~kb}$ ) of the candidate genes. Genomic DNA was extracted from peripheral blood cells using a TIANamp Blood DNA Kit (Tiangen, Beijing) according to the manufacturer's guidelines. DNA libraries were constructed, purified (Ion Torrent, Life Technologies) and sequenced on Ion Torrent PGM using an Ion PGM TM 200 Sequencing Kit, which employed Ion 314 and 
1. Discovery stage

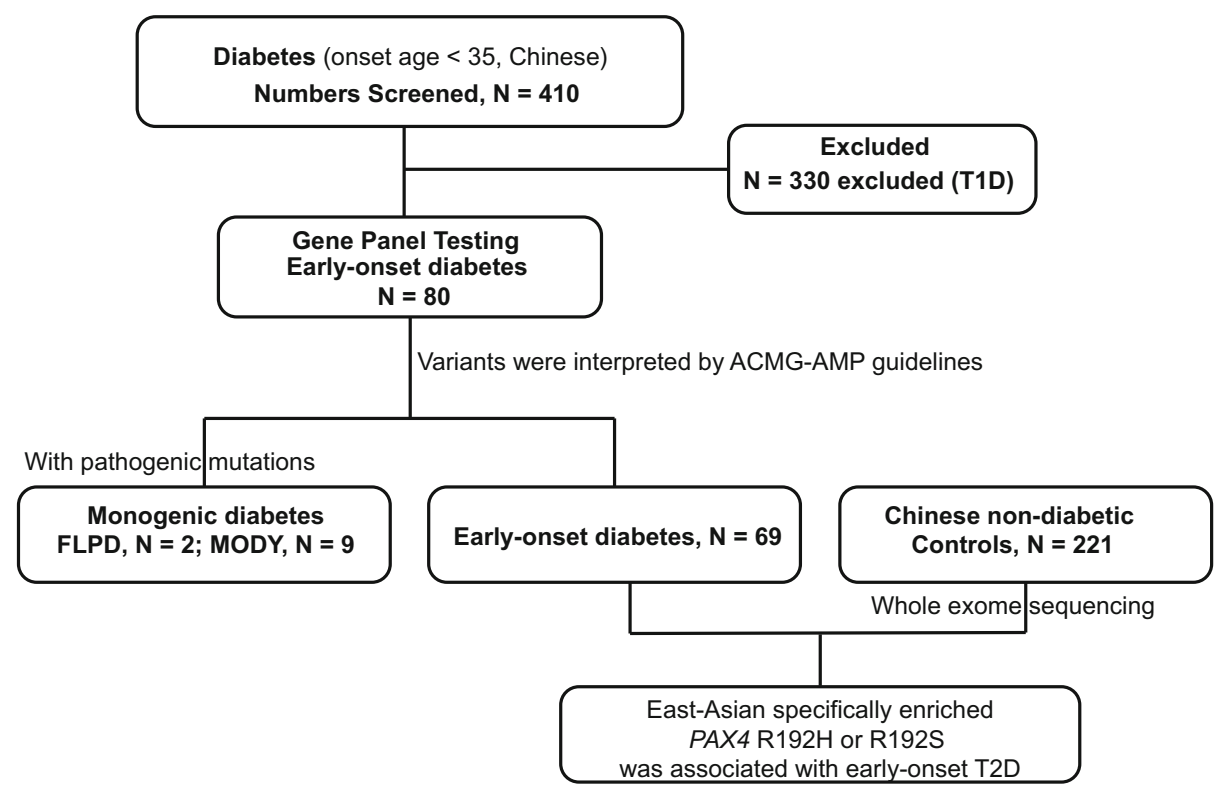

2. Validation stage

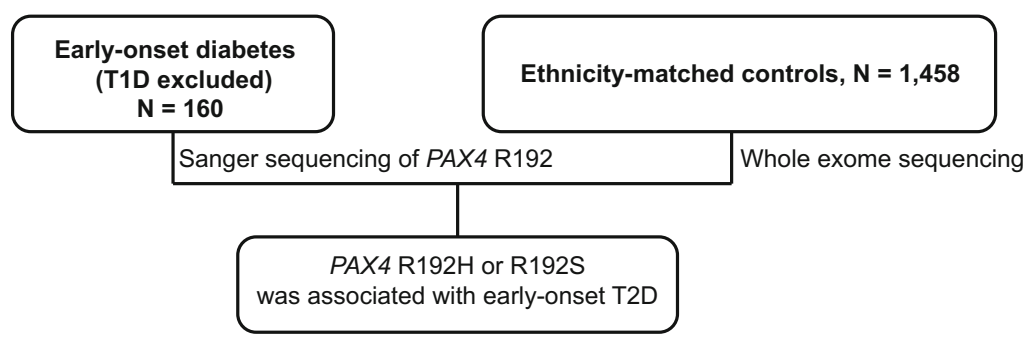

3. Comparisons of clinical features

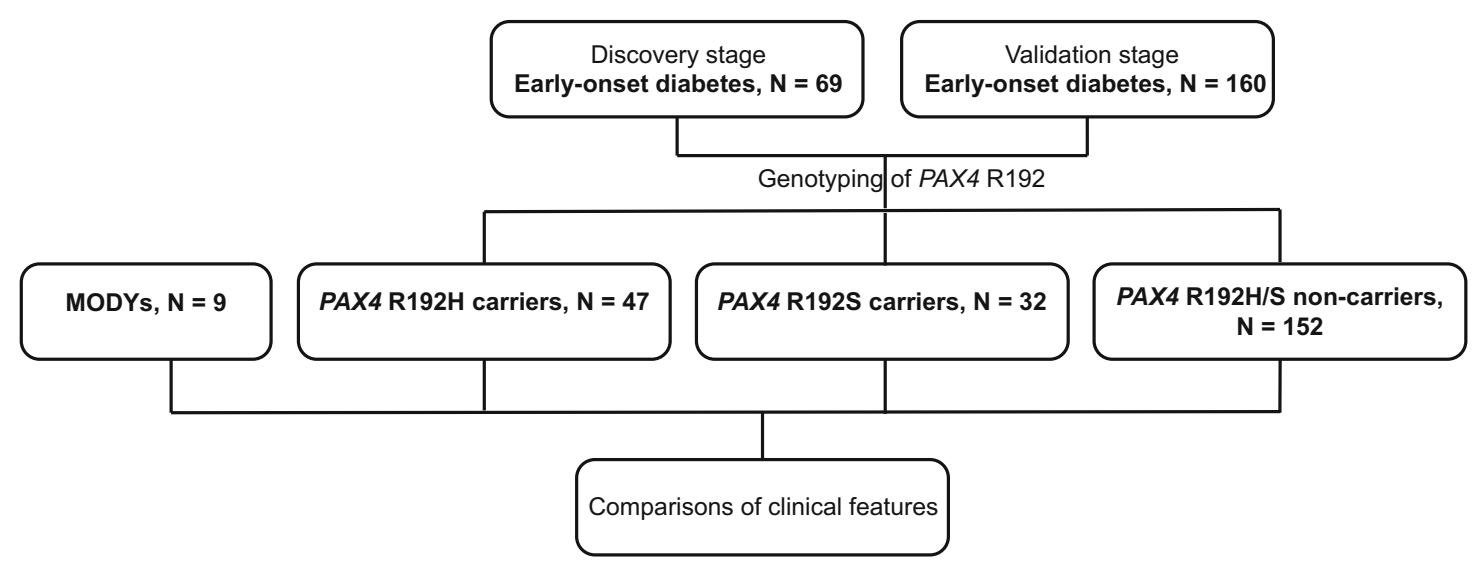


4Fig. 1 Screening flowchart of the research design. TID type 1 diabetes, $M A F$ minor allele frequency, $M O D Y$ maturity-onset diabetes of the young, FPLD familial partial lipodystrophy, $A C M G-A M P$ American College of Medical Genetics and Genomics/Association for Molecular Pathology

Ion 316 chips. The results were mapped to the human genome reference GRCH37 using the Torrent Mapping Alignment Program (TMAP). The Torrent suit software (v2.0) was applied for all analyses.

\section{Analysis of Non-synonymous Variations}

DNA samples were subjected to gene panel testing with the mean base coverage $\geq 20$ times and the depth $\geq 80 \%$ of the target regions selected for analysis. Non-synonymous variations with minor allele frequency (MAF) $<0.05$ in total population, according to the databases [1000 Genomes Project, Exome Aggregation Consortium (ExAC) Project, National Heart, Lung, and Blood Institute Exome Sequencing Project] were verified by Sanger sequencing [21]. The variations were assessed and interpreted according to the American College of Medical Genetics and Genomics/Association for Molecular Pathology (ACMG-AMP) guidelines [22]. If any variation was interpreted as "pathogenic" or "likely pathogenic", the carrier would be diagnosed with the corresponding monogenic diabetes (MD).

\section{Statistical Analysis}

SAS version 9.2 (SAS Institute, USA) was used for data analysis. Quantitative data were described as mean \pm standard deviation (SD) and tested for normal distribution using the Shapiro-Wilk test. The association of $P A X 4 \mathrm{R} 192 \mathrm{H} / \mathrm{S}$ with early-onset diabetes and other counting data was analysed with the chi-square test. Comparisons of clinical characteristics between patients and controls were conducted using the Mann-Whitney $U$ test. Linear regression models were constructed to examine the effects of PAX4 R192 variants on the indicated clinical characteristics with adjustment for age and sex. Mann-Whitney $U$ test was performed to compare C-peptide levels among groups. The allele was subjected to the Hardy-Weinberg equilibrium test using the chi-square test. The results were evaluated at 95\% confidence intervals (CI) with a significance level of $P<0.05$.

\section{Compliance with Ethics Guidelines}

Ethical standard All procedures performed in studies involving human participants were in accordance with the ethical standards of the institutional and/or national research committee (Ethics Committees of Shanghai Ruijin Hospital) and with the 1964 Helsinki declaration and its later amendments or comparable ethical standards. Informed consent was obtained from all individual participants included in the study.

\section{RESULTS}

\section{Detection of Monogenic Diabetes in Early- Onset Diabetes with the Customized Gene Panel}

In the discovery stage, 80 early-onset diabetes patients after the exclusion of T1D were subjected to gene panel testing; the clinical characteristics of these patients are shown in Table S2. Among the 80 early-onset diabetes patients, 11 (13.75\%) had MD genetically diagnosed owing to the presence of pathogenic mutations, including 9 MODYs and 2 familial partial lipodystrophy (FPLD) with high insulin resistance (HOMA-IR were 3.38 and 12.46, respectively) (Table S3). Of the nine MODYs patients, six (66.67\%) had MODY3 diagnosed, and three had MODY7, MODY1 and MODY4 diagnosed, respectively (Table S3). Aside from the known pathogenic mutations [23-27], four novel pathogenic mutations of MODY3/4/7 and one novel pathogenic mutation of FPLD3 were detected by gene panel testing (Table S3). 
Table 1 Clinical characteristics of study participants in the discovery stage

\begin{tabular}{|c|c|c|c|}
\hline & Controls $(N=221)$ & Early-onset diabetes $(N=69)$ & $P$ value \\
\hline Age & $21.41 \pm 4.36$ & $21.66 \pm 5.99$ & 0.911 \\
\hline Onset age (years) & - & $20.12 \pm 5.72$ & - \\
\hline $\operatorname{Sex}(M / F)$ & $94 / 127$ & $30 / 39$ & 0.890 \\
\hline $\operatorname{BMI}\left(\mathrm{kg} / \mathrm{m}^{2}\right)$ & $20.25 \pm 1.58$ & $22.40 \pm 2.99$ & $<0.001$ \\
\hline WC $(\mathrm{cm})$ & $72.7 \pm 6.4$ & $79.7 \pm 8.7$ & $<0.001$ \\
\hline $\mathrm{HC}(\mathrm{cm})$ & $91.1 \pm 5.1$ & $92.1 \pm 7.5$ & 0.094 \\
\hline SBP $(\mathrm{mmHg})$ & $110 \pm 12$ & $118 \pm 16$ & $<0.001$ \\
\hline $\mathrm{DBP}(\mathrm{mmHg})$ & $68 \pm 9$ & $75 \pm 10$ & $<0.001$ \\
\hline $\mathrm{FPG}(\mathrm{mmol} / \mathrm{L})$ & $4.7 \pm 0.4$ & $8.1 \pm 2.9$ & $<0.001$ \\
\hline 2hPG (mmol/L) & $5.2 \pm 1.0$ & $16.0 \pm 5.5$ & $<0.001$ \\
\hline $\mathrm{HbA} 1 \mathrm{c} \%$ & $5.3 \pm 0.3$ & $8.9 \pm 2.7$ & $<0.001$ \\
\hline $\mathrm{TG}(\mathrm{mmol} / \mathrm{L})$ & $0.79 \pm 0.37$ & $3.34 \pm 6.17$ & $<0.001$ \\
\hline $\mathrm{TC}(\mathrm{mmol} / \mathrm{L})$ & $4.29 \pm 3.19$ & $4.71 \pm 1.67$ & 0.008 \\
\hline
\end{tabular}

Data are expressed as the mean \pm SD. $P$ values were calculated using Mann-Whitney $U$ test for continuous variables and chi-square tests for categorical variables. Bolded $P$ values reached statistical significance

$M O D Y$ maturity-onset diabetes of the young, $M$ male, $F$ female, $B M I$ body mass index, $W C$ waist circumference, $H C$ hip circumference, $S B P$ systolic blood pressure, $D B P$ diastolic blood pressure, FPG fasting plasma glucose, $2 h P G 2-\mathrm{h}$ postprandial glucose, $T G$ triglyceride, $T C$ total cholesterol

\section{Association of PAX4 R192H/S Variant with Early-Onset Diabetes in Chinese Subjects}

After the investigation of pathogenic mutations in 11 MD patients, missense variants in PAX4 in the remaining 69 patients and in 221 age and sex-matched non-diabetic Chinese controls were further analysed $[15,28]$. Clinical features of cases and controls are shown in Table 1 . Among the missense variants in PAX4, R192H and R192S were associated with early-onset diabetes [R192H: odds ratio (OR) $2.22,95 \% \mathrm{CI}$ $1.14-4.31, P=0.016$; R192S: OR 2.17, 95\% CI 1.02-4.63, $P=0.041]$. As $P A X 4 \mathrm{R} 192 \mathrm{H}$ and R192S were common single-nucleotide polymorphisms in East Asians and the rare variants

Table 2 PAX4 R192H and R192S were associated with early-onset diabetes

\begin{tabular}{|c|c|c|c|c|c|c|c|c|}
\hline \multirow[t]{3}{*}{ Stage } & \multicolumn{4}{|c|}{$P A X 4 \mathrm{R} 192 \mathrm{H} ;$ c. $575 \mathrm{C}>\mathrm{T} ; \mathrm{rs} 2233580$} & \multicolumn{4}{|c|}{ PAX4 R192S; c. 574 G > T; rs3824004 } \\
\hline & \multicolumn{2}{|l|}{$\overline{\text { MAF }}$} & \multirow[t]{2}{*}{$P$ values } & \multirow[t]{2}{*}{ OR } & \multicolumn{2}{|l|}{ MAF } & \multirow[t]{2}{*}{$P$ values } & \multirow[t]{2}{*}{ OR } \\
\hline & Case & Control & & & Case & Control & & \\
\hline Discovery & 0.116 & 0.056 & 0.016 & $2.22(1.14-4.31)$ & 0.087 & 0.042 & 0.041 & $2.17(1.02-4.63)$ \\
\hline Validation & 0.113 & 0.065 & 0.001 & $1.83(1.25-2.67)$ & 0.072 & 0.047 & 0.047 & $1.58(1.00-2.50)$ \\
\hline Combination & 0.114 & 0.064 & $8.41 \times 10^{-5}$ & $1.88(1.37-2.60)$ & 0.076 & 0.046 & 0.005 & $1.71(1.17-2.51)$ \\
\hline
\end{tabular}

$P$ values were calculated using chi-square tests. Bolded $P$ values reached statistical significance

$M A F$ minor allele frequency, $O R$ odds ratio, $C I$ confidence interval 
in Europeans in Exac databases, the two risk loci in PAX4 may be involved in the different susceptibilities of early-onset diabetes in young East Asians and Europeans (Table 2).

To confirm this finding, the frequencies of PAX4 R192H and R192S were further analysed in an additional 160 Chinese early-onset diabetes (T1D excluded) subjects and 1458 controls [16]. Consistently, both R192H and R192S variants were associated with early-onset diabetes in the validation phase (R192H: OR 1.83, 95\% CI 1.25-2.67, $P=0.001$; R192S: OR 1.58, 95\% CI 1.00-2.50, $P=0.047$ ) (Table 2). The combined results of two stages showed that $\mathrm{R} 192 \mathrm{H} / \mathrm{S}$ was associated with an increased risk of early-onset diabetes (R192H: OR 1.88, 95\% CI 1.37-2.60, $P=8.41 \times 10^{-5}$; R192S: OR 1.71, 95\% CI 1.17-2.51, $P=0.005$ ) (Table 2).

\section{PAX4 R192H and R192S Are Associated with Lower C-Peptide Levels in Early- Onset Patients}

We then compared the metabolic characteristics of PAX4 R192H/S carriers with non-carriers in the early-onset diabetes patients (T1D and MD excluded) from both discovery and validation stages and with MODYs (Table 3). R192H/S carriers with early-onset diabetes were older at onset age, had higher trends in BMI and waist circumference and had higher diastolic blood pressure (DBP) compared with MODY patients. But no significant difference was observed in blood glucose and HbA1c levels between the two groups (Table 3 ).

PAX4 R192H carriers had higher HbA1c levels $(P=0.030)$ and lower $2 \mathrm{~h}$ C-peptide levels in OGTT $(P=0.040)$ than non-carriers (Table 3 and Fig. 2) in early-onset diabetes patients. More importantly, R192S carriers had lower FCP $(P=0.011)$, lower $2 \mathrm{~h}$ C-peptide $(P=0.033)$ and lower area under the curve (AUC) of C-peptide levels $(P=0.015)$ than non-carriers with earlyonset diabetes patients. PAX4 R192H or R192S carriers showed lower FCP $(P=0.032), 2 \mathrm{~h}$ C-Peptide $(P=0.004)$ and AUC of C-peptide $(P=0.004)$ levels than non-carriers in diabetes patients, but presented comparable levels of C-peptide with MODYs (Fig. 2). The PAX4 192 amino acid was determined by the combination c. $575 \mathrm{C}>\mathrm{T}$ and c.574G $>\mathrm{T}$ : R/R, R/H, R/S, H/S, $\mathrm{H} / \mathrm{H}$ and $\mathrm{S} / \mathrm{S}$ (Table S4). The changes of PAX4 192 amino acid by c.575C $>\mathrm{T}$ and/or c.574G $>\mathrm{T}$ were associated with lower FCP levels in early-onset diabetes patients $(\beta=$ - 0.33, 95\% CI - 0.60 to $-0.07, P=0.015$ ) (Table S4). These results imply that PAX4 R192H/S variant carriers with early-onset diabetes have a moderate impairment of islet cell function comparable to that of MODY patients.

\section{DISCUSSION}

In the present study, we developed a customized gene panel to explore the genetic traits in Chinese patients with early-onset diabetes. We identified nine MODY and two FPLD patients with five novel mutations in 80 patients with early-onset diabetes after the exclusion of T1D patients. We further genotyped PAX4 R192H/S in 229 early-onset diabetes (T1D excluded) patients and 1679 non-diabetes controls and found that the East Asian specifically enriched PAX4 R192H/S was associated with an increased risk of early-onset diabetes with decreased C-peptide levels.

In the present study, we detected the presence of MODY1/3/4/7, of which MODY3 (6/9) was the most common type, but MODY2 was undetected, which is consistent with the findings of a previous study on MODY in Chinese patients [29]. Previous studies have shown that MODY3 with mutations in HNF1 $\alpha$ and MODY2 with mutations in GCK were the two major types of MODYs among Caucasians and Koreans [30]. In addition, four novel pathogenic mutations of MODY3/4/7 were detected in our study. With genotyping diagnosis, six MODY3 patients and one MODY1 patient were recommended to receive hypoglycemic sulfonylurea treatment, as they were more sensitive to sulfonylurea than to other drugs [3]. These findings indicate that the gene panel contributes to the detection of novel mutations and effectively benefits the diagnosis and precise treatment of MD.

Previous studies focused on the relatively older T2D patients (mean age $>40$ or 50 years) 
Table 3 Comparisons of clinical characteristics among $P A X 4 \mathrm{R} 192 \mathrm{H} / \mathrm{S}$ carriers, non-carriers in early-onset diabetes and MODYs patients

\begin{tabular}{|c|c|c|c|c|c|}
\hline & $\begin{array}{l}\text { PAX4 R192H } \\
\text { carrier }(N=47)\end{array}$ & $\begin{array}{l}P A X 4 \mathrm{R} 192 \mathrm{~S} \\
\text { carrier }(N=32)\end{array}$ & $\begin{array}{l}P A X 4 \mathrm{R} 192 \mathrm{H} / \mathrm{S} \\
\text { carrier }(N=77)\end{array}$ & $\begin{array}{l}P A X 4 \mathrm{R} 192 \mathrm{H} / \mathrm{S} \\
\text { non-carrier }(N=152)\end{array}$ & $\begin{array}{l}\text { MODYs } \\
(N=9)\end{array}$ \\
\hline Age & $23.85 \pm 6.81$ & $23.47 \pm 5.66$ & $23.62 \pm 6.40$ & $23.59 \pm 6.58$ & $20.22 \pm 5.78$ \\
\hline Onset age & $22.81 \pm 6.66$ & $23.16 \pm 5.62$ & $22.87 \pm 6.28$ & $22.33 \pm 6.48$ & $17.78 \pm 5.52^{8}$ \\
\hline Gender $(\mathrm{M} / \mathrm{F})$ & $33 / 14$ & $23 / 9$ & $54 / 23$ & $86 / 66$ & $3 / 6$ \\
\hline BMI $\left(\mathrm{kg} / \mathrm{m}^{2}\right)$ & $25.29 \pm 5.16$ & $24.13 \pm 3.72$ & $24.83 \pm 4.7$ & $24.93 \pm 4.47$ & $20.99 \pm 2.97$ \\
\hline WC $(\mathrm{cm})$ & $91.8 \pm 18.6$ & $85.7 \pm 9.7$ & $89.4 \pm 15.8$ & $84.2 \pm 14.7$ & $73.2 \pm 6.6$ \\
\hline $\mathrm{HC}(\mathrm{cm})$ & $98.7 \pm 11.8$ & $97.0 \pm 7.1$ & $98.1 \pm 10.2$ & $96.1 \pm 8.3$ & $88.5 \pm 3.9$ \\
\hline $\mathrm{SBP}(\mathrm{mmHg})$ & $122 \pm 16$ & $125 \pm 14$ & $123 \pm 15$ & $122 \pm 15$ & $112 \pm 13$ \\
\hline $\mathrm{DBP}(\mathrm{mmHg})$ & $77 \pm 11$ & $79 \pm 9$ & $78 \pm 10$ & $75 \pm 11$ & $69 \pm 3^{8}$ \\
\hline $\mathrm{FPG}(\mathrm{mmol} / \mathrm{L})$ & $9.0 \pm 2.9$ & $8.4 \pm 3.6$ & $8.8 \pm 3.2$ & $8.5 \pm 3.5$ & $7.4 \pm 3.1$ \\
\hline $2 \mathrm{hPG}(\mathrm{mmol} / \mathrm{L})$ & $15.1 \pm 4.5$ & $14.9 \pm 6.6$ & $15.1 \pm 5.5$ & $15.8 \pm 5.6$ & $12.2 \pm 5.8$ \\
\hline HbAlc (\%) & $10.4 \pm 2.7^{*}$ & $9.0 \pm 2.7$ & $9.9 \pm 2.8$ & $9.2 \pm 2.7$ & $8.1 \pm 3.4$ \\
\hline $\mathrm{TG}(\mathrm{mmol} / \mathrm{L})$ & $2.74 \pm 2.47$ & $2.15 \pm 1.40$ & $2.54 \pm 2.15$ & $2.30 \pm 2.78$ & $1.29 \pm 0.64$ \\
\hline $\mathrm{TC}(\mathrm{mmol} / \mathrm{L})$ & $4.71 \pm 1.27$ & $4.41 \pm 0.87$ & $4.61 \pm 1.14$ & $4.59 \pm 1.16$ & $3.69 \pm 0.86$ \\
\hline
\end{tabular}

Data are expressed as the mean \pm SD. $P$ values were calculated using linear regression adjusted for age and sex

$M D O D Y$ maturity-onset diabetes of the young, $M$ male, $F$ female, $B M I$ body mass index, $W C$ waist circumference, $H C$ hip circumference, $S B P$ systolic blood pressure, $D B P$ diastolic blood pressure, $F P G$ fasting plasma glucose, 2hPG 2-h postprandial glucose, $T G$ triglyceride, $T C$ total cholesterol

${ }^{*} P$ values $<0.05$ compared with $P A X 4 \mathrm{R} 192 \mathrm{H} / \mathrm{S}$ non-carriers; ${ }^{2} P$ values $<0.05$ compared with $P A X 4 \mathrm{R} 192 \mathrm{H} / \mathrm{S}$ carriers

in Korean, Chinese and Singaporean subjects demonstrated the association of PAX4 R192H/S with T2D [12, 31-33]. Another study on Thai patients found that the frequency of the PAX4 $\mathrm{R} 192 \mathrm{H}$ variant was higher in MODY [34]. However, in the present study, we concentrated on young Chinese diabetic patients (mean age $23.60 \pm 6.51$ years) and found that PAX4 $\mathrm{R} 192 \mathrm{H}$ and R192S variants were associated with early-onset diabetes. Therefore, to the best of our knowledge, our research is the first study to report the missense variants $\mathrm{R} 192 \mathrm{H} / \mathrm{S}$ of $P A X 4$ associated with early-onset diabetes in the young Chinese population. Some previous studies also reported that PAX4 R192H was associated with a younger onset age of T2D [32-34]. However, we did not observe an younger onset age in $P A X 4 \mathrm{R} 192 \mathrm{H} / \mathrm{S}$ carriers but found a higher OR of $P A X 4 \mathrm{R} 192 \mathrm{H}$ (OR 1.88) than those in the previous studies (OR 1.39 or 1.48) $[32,33]$. This may be due to the younger and narrower age range of the subjects enrolled in our study compared with the previous ones $[32,33]$.

Paired-homeodomain transcription factor $P A X 4$ is a member of the paired box (PAX) family and located at chromosome $7 q 32$. It plays an important role in the development, differentiation, expansion and survival of islet insulin-producing $\beta$-cells $[8,9]$. During the early developmental stage of the pancreas, the PAX4 gene suppresses the transcription activities of insulin, glucagon, somatostatin, islet amyloid polypeptide and ghrelin promoters mainly in the $\alpha$-cells, thus repressing $\alpha$-cell differentiation and permitting $\beta$-cell differentiation $[10,35]$. In the pancreas of PAX4 homozygous mutant mice, insulin-producing $\beta$-cells and 

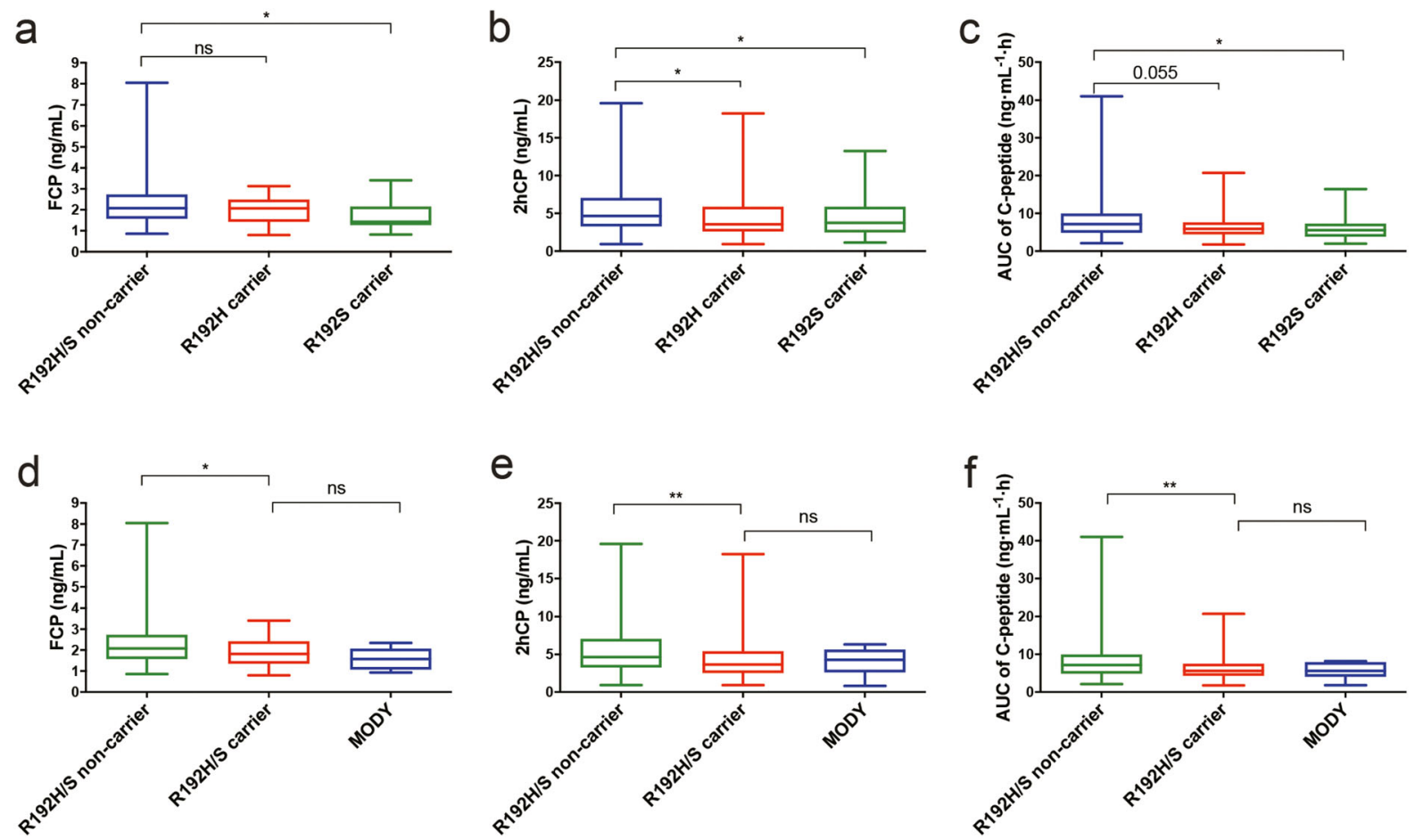

Fig. 2 Serum C-peptide levels among the diabetic patients with different phenotypes of PAX4. FCP levels (a), $2 \mathrm{hCP}$ levels (b) and AUC of C-peptide levels (c) of R192S/H non-carriers, R192H carriers and R192S carriers; FCP levels (d), 2hCP levels (e) and AUC of C-peptide levels (f) of R192S/H non-carriers, R192H/S carriers and MODY patients. FCP fasting C-peptide, $2 h C P \quad 2 \mathrm{~h}$

postprandial C-peptide, $A U C$ area under curve, $M O D Y$ maturity-onset diabetes of the young, ns no significance. Mann-Whitney $U$ test was used for the data analysis. Data are expressed with box and whiskers (minimum to maximum). ${ }^{*} P<0.05 ;{ }^{* *} P<0.01 ;{ }^{* * *} P<0.001$

somatostatin-producing $\delta$-cells are absent, but the population of glucagon-producing $\alpha$-cells is high [8]. Moreover, insulin protein levels increase, whereas glucagon protein levels remain constant in Pax4-overexpressing islets, and PAX4 mRNA expression is elevated in human insulinomas [36, 37]. In 2007 and 2011, pathogenic mutations in PAX4 were shown to lead to MODY9 in Thai and Japanese patients, respectively [34, 38]. Previous functional experiments have shown that PAX4 R192H can reduce the repression abilities of insulin and glucagon promoters and impair $\beta$-cell development and survival $[10,11]$, consistent with lower C-peptide levels in PAX4 R192H carriers, which may lead to a higher HbA1c level than in non-carriers as reported in our study. More importantly, PAX4 R192S carriers showed lower FCP and $2 \mathrm{~h}$ C-peptide levels in early-onset diabetes patients. As far as we know, this study is the first report to describe that PAX4 R192S carriers tend to have lower C-peptide levels in diabetes.

East Asians are more susceptible to earlyonset diabetes than Europeans [5] and exhibit reduced insulin secretion at earlier stages [7]. In the present study, PAX4 R192H/S was associated with early-onset diabetes in Chinese and lower C-peptide levels in early-onset diabetes patients. Also, different ethnicities have distinct frequencies of PAX4 R192H and R192S according to the database gnomAD v2.1.1, the two variants are specifically higher in East Asians $(\mathrm{R} 192 \mathrm{H}, \quad \mathrm{MAF}=0.109 ; \mathrm{R} 912 \mathrm{~S}, \quad \mathrm{MAF}=0.039)$. However, the frequencies of the variants were extremely low in Europeans (MAF $<0.000$ ). Therefore, we presume that the East Asianspecific enrichment of PAX4 R192H/S may be 
one explanation for the differences in diabetes between the East and the West.

Our study was limited with a relatively small sample size. Hence, a large-scale study of the early-onset diabetes population from East Asia is needed to validate our findings. It may also be important to develop a humanized PAX4 R192H/S variant knock-in mouse model to illustrate the causality between the two risk variants and diabetes and the pathogenic mechanism that underlies early-onset diabetes.

\section{CONCLUSIONS}

In summary, we explored the genetic architecture of early-onset diabetes in Chinese subjects by applying a customized gene panel. We further identified that the East Asian-specifically enriched variants PAX4 R192H and R192S predisposed carriers to early-onset diabetes with a reduction of insulin secretion, partially explaining the discrepancy of diabetes between the East and the West from a genetic perspective.

\section{ACKNOWLEDGEMENTS}

We thank the investigators and participants involved in our study, who made this report possible.

Funding This study and the journal's rapid service fee were supported by grants from National Key R\&D Program of China (2018YFC1314800, 2016YFC1305202, 2018YFC1313800) and Shanghai Municipal Education Commission-Gaofeng Clinical Medicine Grant Support (20161403). 19DZ2340300 from Science and Technology Commission of Shanghai Municipality.

Authorship All named authors meet the International Committee of Medical Journal Editors (ICMJE) criteria for authorship for this article, take responsibility for the integrity of the work as a whole, and have given their approval for this version to be published.
Medical writing and/or editorial assistance We thank Elsevier for their help in the English language editing of this manuscript.

Disclosures Aibo Gao, Bin G, Juan Zhang, Chen Fang, Junlei Su, Haorong Li, Rulai Han, Lei Ye, Weiqing Wang, Guang Ning, Jiqiu Wang and Weiqiong $\mathrm{Gu}$ have nothing to disclose.

Compliance with ethics guidelines All procedures performed in studies involving human participants were in accordance with the ethical standards of the institutional and/or national research committee (Ethics Committees of Shanghai Ruijin Hospital) and with the 1964 Helsinki Declaration and its later amendments or comparable ethical standards. Informed consent was obtained from all individual participants included in the study.

Data availability Data described in the manuscript will be made available from the corresponding authors on request, after the request has been submitted and formally reviewed and approved by the Ethics Committee of the Institute of Shanghai Ruijin Hospital, Shanghai, China.

Open Access. This article is licensed under a Creative Commons Attribution-NonCommercial 4.0 International License, which permits any non-commercial use, sharing, adaptation, distribution and reproduction in any medium or format, as long as you give appropriate credit to the original author(s) and the source, provide a link to the Creative Commons licence, and indicate if changes were made. The images or other third party material in this article are included in the article's Creative Commons licence, unless indicated otherwise in a credit line to the material. If material is not included in the article's Creative Commons licence and your intended use is not permitted by statutory regulation or exceeds the permitted use, you will need to obtain permission directly from the copyright holder. To view a copy of this licence, visit http://creativecommons.org/licenses/bync/4.0/. 


\section{REFERENCES}

1. Yeung RO, Zhang Y, Luk A, et al. Metabolic profiles and treatment gaps in young-onset type 2 diabetes in Asia (the JADE programme): a cross-sectional study of a prospective cohort. Lancet Diabetes Endocrinol. 2014;2:935-43.

2. Lee SC, Ko GTC, Li JKY, et al. Factors predicting the age when type 2 diabetes is diagnosed in Hong Kong Chinese subjects. Diabetes Care. 2001;24: 646-9.

3. Ellard S, Bellanné-Chantelot C, Hattersley AT. Best practice guidelines for the molecular genetic diagnosis of maturity-onset diabetes of the young. Diabetologia. 2008;51:546-53.

4. Ma RCW, Chan JCN. Type 2 diabetes in East Asians: similarities and differences with populations in Europe and the United States. Ann Ny Acad Sci. 2013;1281:64-91.

5. Yoon K-H, Lee J-H, Kim J-W, et al. Epidemic obesity and type 2 diabetes in Asia. Lancet. 2006;368: 1681-8.

6. Chan JCN, Malik V, Jia W, et al. Diabetes in Asia. JAMA. 2009;301:2129.

7. Fukushima M, Suzuki H, Seino Y. Insulin secretion capacity in the development from normal glucose tolerance to type 2 diabetes. Diabetes Res Clin Pr. 2004;66:S37-43.

8. Sosa-Pineda B, Chowdhury K, Torres M, Oliver G, Gruss P. The Pax4 gene is essential for differentiation of insulin-producing $\beta$ cells in the mammalian pancreas. Nature. 1997;386:399.

9. Brun T, Gauthier BR. A focus on the role of Pax4 in mature pancreatic islet $\beta$-cell expansion and survival in health and disease. J Mol Endocrinol. 2008;40:37-45.

10. Sujjitjoon J, Kooptiwut S, Chongjaroen N, et al. PAX4 R192H and P321H polymorphisms in type 2 diabetes and their functional defects. J Hum Genet. 2016;61:943.

11. Kooptiwut S, Plengvidhya N, Chukijrungroat $\mathrm{T}$, et al. Defective PAX4 R192H transcriptional repressor activities associated with maturity onset diabetes of the young and early onset-age of type 2 diabetes. J Diabetes Complicat. 2012;26:343-7.

12. Spracklen CN, Horikoshi M, Kim YJ, et al. Identification of type 2 diabetes loci in 433,540 East Asian individuals. Nature. 2020;582:240-5.
13. Gragnoli C, Cockburn BN, Chiaramonte F, et al. Early-onset type II diabetes mellitus in Italian families due to mutations in the genes encoding hepatic nuclear factor $1 \mathrm{a}$ and glucokinase. Diabetologia. 2001;44:1326-9.

14. Group SS. SEARCH for Diabetes in Youth: a multicenter study of the prevalence, incidence and classification of diabetes mellitus in youth. Control Clin Trials. 2004;25:458-71.

15. Liu R, Zou Y, Hong J, et al. Rare loss-of-function variants in NPC1 predispose to human obesity. Diabetes. 2017;66:935-47.

16. Tang $\mathrm{H}$, Jin $\mathrm{X}, \mathrm{Li} \mathrm{Y}$, et al. A large-scale screen for coding variants predisposing to psoriasis. Nat Genet. 2014;46:45.

17. American Diabetes Association: 2. Classification and diagnosis of diabetes. Diabetes Care. 2017;40: S11-24.

18. Gu W, Hu J, Wang W, et al. Diabetic ketoacidosis at diagnosis influences complete remission after treatment with hematopoietic stem cell transplantation in adolescents with type 1 diabetes. Diabetes Care. 2012;35:1413-9.

19. Liu R, Hong J, Xu X, et al. Gut microbiome and serum metabolome alterations in obesity and after weight-loss intervention. Nat Med. 2017;23: 859-68.

20. Bonnefond A, Froguel P. Rare and common genetic events in type 2 diabetes: what should biologists know? Cell Metab. 2015;21:357-68.

21. Wessel J, Chu AY, Willems SM, et al. Low-frequency and rare exome chip variants associate with fasting glucose and type 2 diabetes susceptibility. Nat Commun. 2015;6:5897.

22. Richards S, Aziz N, Bale S, et al. Standards and guidelines for the interpretation of sequence variants: a joint consensus recommendation of the American College of Medical Genetics and Genomics and the Association for Molecular Pathology. Genet Med. 2015;17:405-23.

23. Johansson $S$, Irgens $H$, Chudasama KK, et al. Exome sequencing and genetic testing for MODY. PLoS ONE. 2012;7:e38050.

24. Xu J, Chan V, Zhang W, Wat N, Lam K. Mutations in the hepatocyte nuclear factor- $1 \alpha$ gene in Chinese MODY families: prevalence and functional analysis. Diabetologia. 2002;45:744-6.

25. Lambert AP, Ellard S, Allen LIS, et al. Identifying hepatic nuclear factor 1 mutations in children and 
young adults with a clinical diagnosis of type 1 diabetes. Diabetes Care. 2003;26:333-7.

26. Xu JY, Dan QH, Chan V, et al. Genetic and clinical characteristics of maturity-onset diabetes of the young in Chinese patients. Eur J Hum Genet. 2005; 13:422.

27. Schmidt HHJ, Genschel J, Baier P, et al. Dyslipemia in familial partial lipodystrophy caused by an R482W mutation in the LMNA gene. J Clin Endocrinol Metab. 2001;86:2289-95.

28. Zou Y, Lu P, Shi J, et al. IRX3 promotes the browning of white adipocytes and its rare variants are associated with human obesity risk. EBioMedicine. 2017;24:64-75.

29. Zhang M, Zhou JJ, Cui W, et al. Molecular and phenotypic characteristics of maturity-onset diabetes of the young compared with early onset type 2 diabetes in China. J Diabetes. 2015;7:858-63.

30. Hwang JS, Shin CH, Yang SW, Jung SY, Huh N. Genetic and clinical characteristics of Korean maturity-onset diabetes of the young (MODY) patients. Diabetes Res Clin Pract. 2006;74:75-81.

31. Ang SF, Tan CSH, Wang L, et al. PAX4 R192H is associated with younger onset of Type 2 diabetes in East Asians in Singapore. J Diabetes Complicat. 2019;33:53-8.

32. Kwak SH, Chae J, Lee S, et al. Nonsynonymous variants in PAX4 and GLP1R are associated with type 2 diabetes in an East Asian population. Diabetes. 2018;67:1892-902.

33. Cheung CY, Tang CS, Xu A, et al. Exome-chip association analysis reveals an Asian-specific missense variant in PAX4 associated with type 2 diabetes in Chinese individuals. Diabetologia. 2017;60: 107-15.

34. Plengvidhya N, Kooptiwut S, Songtawee N, et al. PAX4 Mutations in Thais with maturity onset diabetes of the young. J Clin Endocrinol Metab. 2007;92:2821-6.

35. Smith SB, Ee HC, Conners JR, German MS. Pairedhomeodomain transcription factor PAX4 acts as a transcriptional repressor in early pancreatic development. Mol Cell Biol. 1999;19:8272-80.

36. Brun T, Franklin I, St-Onge L, et al. The diabeteslinked transcription factor PAX4 promotes $\beta$-cell proliferation and survival in rat and human islets. J Cell Biol. 2004;167:1123-35.

37. Miyamoto $\mathrm{T}$, Kakizawa $\mathrm{T}$, Ichikawa $\mathrm{K}$, et al. Expression of dominant negative form of PAX4 in human insulinoma. Biochem Biophys Res Commun. 2001;282:34-40.

38. Jo W, Endo M, Ishizu K, Nakamura A, Tajima T. A novel PAX4 mutation in a Japanese patient with maturity-onset diabetes of the young. Tohoku J Exp Med. 2011;223:113-8. 